\title{
Extraction and Capture of Water from Martian Regolith Experimental Proof-of-Concept
}

\author{
Diane L. Linne ${ }^{1}$, Julie E. Kleinhenz ${ }^{2}$, Steven W. Bauman ${ }^{3}$, Kyle A. Johnson ${ }^{4}$ \\ NASA Glenn Research Center, Cleveland, $\mathrm{OH}, 44135$
}

\begin{abstract}
A novel concept for extraction of water from the Mars soil in a real-time, open-air process was demonstrated in a Mars environment chamber. The concept breadboard uses radiative heating to bake off water from exposed soil contained in a bin. An enclosure, intended to mimic the bottom of a rover, covers the bin. A fan continuously blows the Mars atmospheric gases through the enclosure to collect the evolved water while a tiller was used to churn up moist subsurface soil. These initial tests verified concept feasibility. The sweep gas generated by commercially available muffin fans at 7 Torr was sufficient to transfer water vapor into a condenser flow loop. The radiative heating, while non-optimized, heated the soil surface to $60^{\circ} \mathrm{C}$ to generate water vapor. A rototiller working through the soil bin brought sufficient amounts of new moist soil to the heated surface to show an increase in rate of water extraction.
\end{abstract}

\section{Nomenclature}

DVR $=$ digital video recorder

ISRU $\quad=$ in-situ resource utilization

\section{Introduction}

$\mathrm{T}$ HE concept of using available resources at an exploration site to make propellant and life support consumables, known as in-situ resource utilization (ISRU), is often referred to as a game-changing, but high-risk technology. NASA's current plans for human exploration of Mars is based on the extensive work performed by the Mars Architecture Working Group and documented in Mars Design Reference Architecture (DRA) 5.0. ${ }^{1,2}$ For the first time this document names ISRU production of oxygen from the Mars atmosphere (for ascent propulsion and crew consumables) as enabling for robust human exploration missions. While production of methane from ground water and atmospheric carbon dioxide was also evaluated, it was not included in the baseline due to "limited concept evaluation to date and Mars surface water property and distribution uncertainty." Since that report was published in 2008, Mars missions such as Odyssey, Phoenix, and Curiosity have confirmed that water can be found globally across the Mars surface, and that there are regions with up to 8 to 10 percent water by mass in the top $1 \mathrm{~m}$ of the regolith. So while there is more confidence that sufficient water can be found at the desired exploration site, there has been little progress made in defining concepts for extraction and capture of this valuable resource. Therefore the technology readiness level remains too low to support higher fidelity system studies of a Mars fuel production plant.

The Mars DRA 5.0 report compares water extraction from the Mars soil to oxygen extraction from the lunar regolith, where oxygen is extracted in a batch process at high temperature with the aid of a working fluid that must be recycled. ${ }^{3,4}$ Due to the low yield ( $\sim 2$ percent of the regolith mass) and high-energy expenditure (in terms of power, excavation, etc.), all current lunar concepts include sealed reactors to capture every precious molecule. However, repeated sealing of hot surfaces that are constantly exposed to abrasive regolith has proved to be one of the biggest technology challenges for lunar oxygen and water production. This new approach to mining soil water on Mars is to use the Mars atmosphere as a sweep gas in an 'open-air' process that will continually harvest the water as the rover/excavator roams the planet. While this process may 'lose' some of the evolved water, it eliminates the need for reusable, high-temperature, dusty seals, and provides heat at the granular level to reduce long heating times

\footnotetext{
${ }^{1}$ Senior Research Engineer, Propulsion Division, MS 301-3, AIAA Associate Fellow.

${ }^{2}$ Research Engineer, Propulsion Division, MS 301-3, AIAA Senior Member.

${ }^{3}$ Research Engineer, Materials and Structures Division, MS 23-2.

${ }^{4}$ Robotics Systems Engineer, Materials and Structures Division, MS 23-3.
} 
and the resultant loss of energy to the environment. The overall system simplicity should prove the concept to be a very attractive option.

To test the feasibility of this 'open-air' mining concept, breadboard hardware was built and tested in a Mars environment chamber. The concept uses radiative heating to bake off water from exposed soil contained in a bin. An enclosure, intended to mimic the bottom of a rover, covers the bin. A fan continuously blows the Mars atmospheric gases through the enclosure to collect the evolved water. A tiller was also available within the enclosure to churn up moist subsurface soil. The design and initial test results of this concept are presented in this paper.

\section{Test Facility}

All tests were conducted in the Mars Atmosphere Chemistry Simulation chamber (MACS) (Fig. 1), a stainless steel bell jar with a $200-\mathrm{L}$ volume designed to simulate atmospheric conditions on the Martian surface. One of the key design features of the MACS chamber is that all of the feedthroughs enter the chamber from the bottom so the bell can be lifted cleanly off of the base plate. This allowed easy access to the test hardware and ability to quickly remove 'spent' simulant bins and replace with a freshly prepared simulant bin.

After initial pump-down, the chamber can be filled with a controlled composition of carbon dioxide, nitrogen, and argon to simulate the composition of the Mars atmosphere. Flow control valves on each gas line allow setting the flow rate of each gas into the chamber. The chamber pressure is maintained dynamically with a back-pressure valve controlling the evacuation through an oil-free scroll pump. A complete thermal shroud and a $40-\mathrm{cm}$ diameter cold plate are both available to chill the environment and hardware. However, for the initial feasibility tests reported here all hardware and simulant were at ambient conditions.

Test data was recorded at approximately $0.5 \mathrm{~Hz}$ using Labview. A low light, miniature CCD camera was mounted inside the test enclosure and test video was recorded on a DVR.

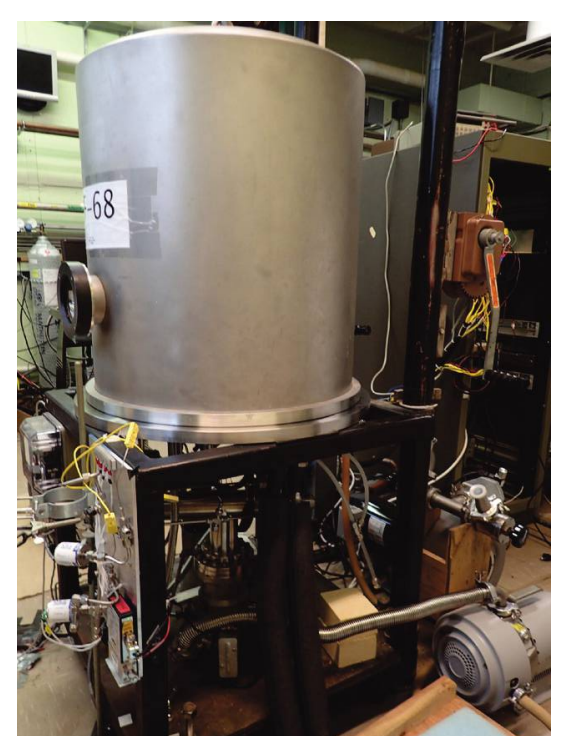

Figure 1. Mars Atmosphere Chemistry Simulation Chamber (MACS).

\section{Experimental Hardware}

The test hardware consisted of an enclosure that housed the soil bin and heaters, an excavation implement to continually expose fresh simulant for extraction of water, and a flow loop to capture and measure the evolved water.

\section{A. Enclosure}

The $25-\mathrm{cm}$ wide by $43-\mathrm{cm}$ long by $14-\mathrm{cm}$ deep soil bin sits on the cold plate that is $9 \mathrm{~cm}$ above the floor of the chamber to allow access to the feedthroughs. The bin is enclosed by two Teflon plates resting on the long sides of the bin, and a curved aluminum sheet at each end. Together these pieces form a complete enclosure $30 \mathrm{~cm}$ tall. On top of this enclosure are two removable heated plates that each provide up to $500 \mathrm{~W}$; the bottom of the heater plates are painted with a flat black paint to enhance emissivity during the near vacuum heating. An outside view of the hardware can be seen in Fig. 2.

\section{B. Excavation Implement}

To increase the efficacy of the extraction concept, a means of excavating moist subsurface soil was needed. For these initial concept feasibility tests a standard rototiller concept was used. While bound water, which was tested in this initial feasibility phase, should be released from the soil at less than $60{ }^{\circ} \mathrm{C}$ at Mars pressures, the harvesting concept must also be able to capture water from hydrated minerals. These hydrated soils may need to be heated up to $300{ }^{\circ} \mathrm{C}$



Figure 2. Outside view of enclosure in test chamber. 
before releasing their water, depending on the mineral types, so the rototiller hardware needed to operate within this high-temperature environment. In addition, the rototiller needed to dig down at least $5 \mathrm{~cm}$ to ensure access to moist soil below a potentially desiccated top layer.

\section{Rototiller Design}

A commercial rototiller was purchased in order to utilize its four rotors for the test rig rototiller (Fig. 3). The $16.5-\mathrm{cm}$ diameter steel rotors were the smallest commercially available unit. Each rotor has six tines and a 45-degree bend near the end to further aid in upsetting the soil.

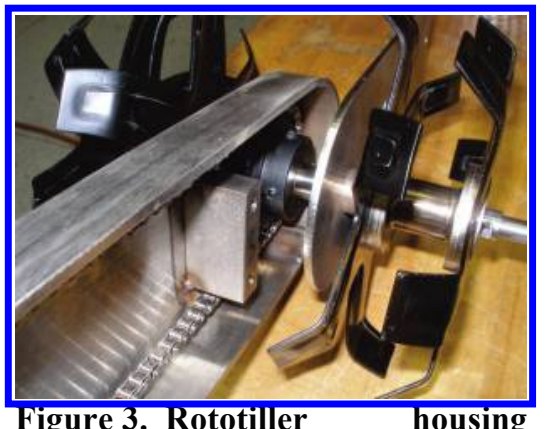

Figure 3. Rototiller housing (cover removed), chain, and sprocket drive, showing all-metal shaft components.

To meet the $300{ }^{\circ} \mathrm{C}$ temperature requirement, the largely plastic mounting and drive shaft components of the commercial rototiller were replaced. The same basic design approach of sandwiching the rotor-shaft components together using a center shaft was emulated using all custommade stainless steel parts. The rotor shaft bearings and drive housing reside at the center of the shaft with two rotors on each side. The rototiller uses a stainless steel (SS) housing, high-temperature dryrunning flanged sleeve bearing, and a $0.64 \mathrm{~cm}$ pitch roller chain and sprocket drive system (Fig 3).

The stainless steel housing has a lengthwise box side and a flat enclosure lid. It is $17.5 \mathrm{~cm}$ wide by $7.6 \mathrm{~cm}$ deep by $44.5 \mathrm{~cm}$ long and is rounded at the shaft end. It provides an axial distance between the rotor shaft and the drive motor of $36.7 \mathrm{~cm}$ such that the drive motor would remain mounted well above the heated enclosure (Fig. 2). The gearreduced drive motor has a chain sprocket and is slot-mounted for proper chain tensioning.

\section{Rotor Motion}

For the initial tests it was desired to have the rototiller move through the soil bin in a straight line and at a constant depth. To achieve this motion, the rototiller was double-hinge mounted to the enclosure structure (Fig. 4)

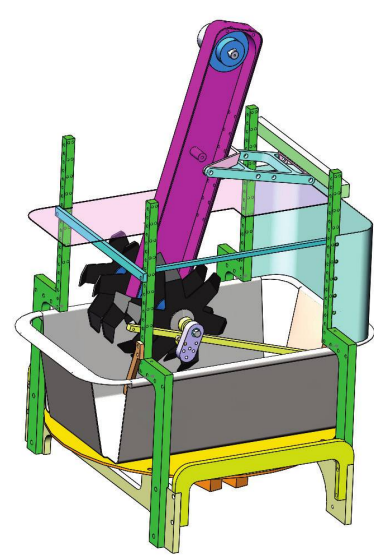

Figure 4. SolidWorks model of full assembly with rototiller. and was driven across the soil bin using a gear and gear rack (Fig. 5). The rototiller shaft extends out one side, and this shaft has a flat portion forming what

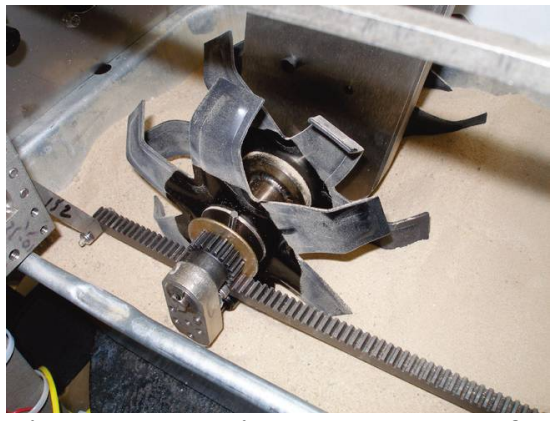

Figure 5. Rototiller assembly for level-drive motion across the soil bin; shown are the tines, gear, gear rack, gear keeper, and track roller. is called a D-profile shaft. On to this a gear is set-screw mounted. This gear is intended to engage with the gear rack such that the rotor rotation will also proportionally drive its own motion across the rack. The gear rack is mounted at each end to the enclosure structure to keep it firm and level relative to the soil bin. To ensure that the gear stays engaged for deeper tilling or harder soils a "Gear Keeper" was added to the shaft end. The Keeper freely rotates on the rototiller shaft and maintains a "Track Roller" on the flat backside of the rack. This prevents the gear from separating from the rack, and it maintains its own proper position independent of the turning shaft and the angularly-changing rototiller. Changing the gear to larger sizes makes the traverse faster. Inverting the rack reverses the direction of the traverse. The rack can be mounted at many different heights relative to the soil by selecting from the available screw holes in the structure.

Although not tested here, other configurations of the mounting and gear hardware can provide different motions, such as a linear arc through the soil or stationary digging. The entire assembly is shown in Fig. 6. 


\section{Rotor Drive and Control}

A commercial-off-the-shelf gearmotor and control system was desired to provide the rotor motion. The gearmotor needed to be capable of providing up to $4 \mathrm{Nm}$ of torque at 20 RPM while operating in a Mars-level vacuum. The torque calculations were based on an estimated geometry and soil conditions using a force prediction model. ${ }^{5}$ A brushless motor configuration was required for the low pressure environment. Integrated control and electronics was also desired for ease of implementation.

A commercial motor with a 216:1 gearbox was chosen to meet these design requirements. This gearmotor configuration is capable of providing $28.3 \mathrm{Nm}$ of torque at $20 \mathrm{RPM}$ and is sufficiently oversized to avoid overheating during operation in a Mars vacuum. This motor has an integrated electronics and control system that allows for low power analog signals to control the speed and direction. The motor has an internal speed controller that is able to accommodate changing load levels. Additionally, the electrical system has built-in overload protections including blockage, thermal, and low/high voltage protections.

\section{Flow Loop and Water Capture}

Key to this concept of 'open air' water extraction and capture is the ability to use the low-pressure Mars atmosphere as a sweep gas to gather the evolved moisture and transport it to a collection device. Previous tests in the MACS chamber showed that a simple muffin fan can create flow even at the low Mars pressures. ${ }^{6}$ A $4-\mathrm{cm}$ diameter fan was set in one end wall of the enclosure to generate a current of Mars atmospheric gases across the surface of the simulant bed. A $15-\mathrm{cm}$ funnel in the opposite end of the enclosure directs the Mars atmospheric gases into the capture flow loop via a $0.95 \mathrm{~cm}$ line in the floor of the chamber (Fig. 6). The fan is rated at $818 \mathrm{lpm}$ flow and $820 \mathrm{~Pa}$ (6.1 Torr) head rise when operating at one standard atmosphere pressure. To further enhance the strength of the gas flow stream, a second fan was placed on the exit of the flow loop inside the chamber such that there was both a push and pulling of the gas stream (Fig. 2).

To capture the water out of the gas flow stream, a simple condenser was used. The condenser consisted of a $0.95 \mathrm{~cm}$ clear tube connected directly to the chamber outlet/inlet lines. This condenser tube passed through an ice-water bath outside of the Mars chamber. For the final condenser configuration, a second tube section was added at a $\mathrm{T}$ in the low point in the line to enlarge the water capture volume. The final condenser configuration submerged in an ice bath is shown in Fig. 7.

It is of interest to note that the original flow loop design included a dryer bed containing indicating desiccant that changes color from blue to pink when saturated with water. The height of the saturated desiccant was intended to indicate water capture as a function of time. A measurement of total water capture in a test was also planned by weighing the desiccant bed before and after each test. Also included in the flow loop were several pressure transducers and thermocouples, and a flow meter. The desiccant bed was purchased as an assembled unit with $0.32 \mathrm{~cm}$ fittings the largest that were available. Because the expected flow rate was very small, the flow meter was sized accordingly and therefore also had very small internal flow passages. Initial tests indicated that little-to-no gas flow was being achieved through the flow loop. Therefore, the desiccant bed, flow meter, and associated plumbing were removed from the loop in favor of the condenser

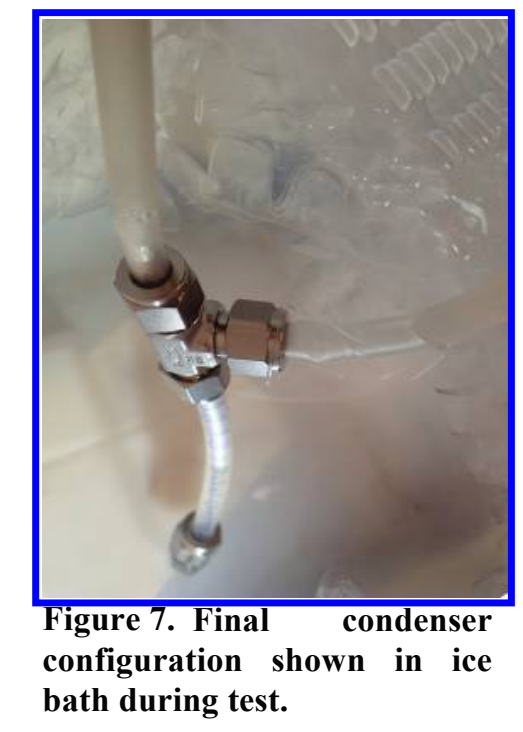
described above. 


\section{Results}

Three sets of tests were conducted to investigate the feasibility of separate aspects of the overall concept: water capture, soil heating, and water extraction from regolith.

\section{A. Water Capture Results}

The first set of tests were intended to verify the functionality of the flow loop and water capture methods. To ensure that the 'air' in the flow enclosure contained sufficient moisture to test the water capture concept, a heated pan of water was used in place of soil in the bin. The water started boiling as the chamber pressure passed below approximately 100 Torr with a corresponding drop in temperature indicating some vaporization of water was occurring during pump-down of the chamber. Once the pressure was stabilized (in the 7 to 15 Torr range) the initial boiling subsided. The heater and fans were then turned on and the boiling restarted when the water reached approximately $20^{\circ} \mathrm{C}$.

The initial water capture tests were conducted with the original desiccant bed in the flow loop. No water was captured in several tests at Mars pressures ( 7 to 10 Torr). In the final test, the vacuum pump was shut down and makeup gas $\left(\mathrm{CO}_{2}\right.$ and $\left.\mathrm{N}_{2}\right)$ was allowed to flow into the chamber to gradually increase chamber pressure while the water was slowly boiling and the fans were turned on. At a chamber pressure of approximately 120 Torr the inlet of the desiccant column began to change color, indicating water being captured. The moisture capture continued slowly as the chamber pressure increased up to 190 Torr, with a height of approximately $0.6 \mathrm{~cm}$ in 13 minutes. Based on the volume of desiccant that changed color, less than $1 \mathrm{gm}$ of water was captured. These tests indicated that either the motive force created by the fans at typical Mars pressures was too small to overcome system pressure drops, or the desiccant does not capture water at low pressure (or some combination). Therefore, the condenser was installed in place of the desiccant bed as described in Section III.

For the remaining water capture tests, the condenser configuration was used for water capture. Water condensation on the tube walls was observed almost immediately when turning on the fans. The much smaller amount of condensation on the tube portion exiting the ice bath as compared to the tube entering the bath was an indication that most of the moisture in the gas stream was being captured (Fig. 8). Because there was a low spot in the condenser loop, the captured water would settle in that portion and eventually block the flow path, preventing any further water capture (Fig. 9). With water boiling during pump-down and vented out the pump line, measurements of total water lost compared to water captured were not an accurate indication of the effectiveness of the capture concept

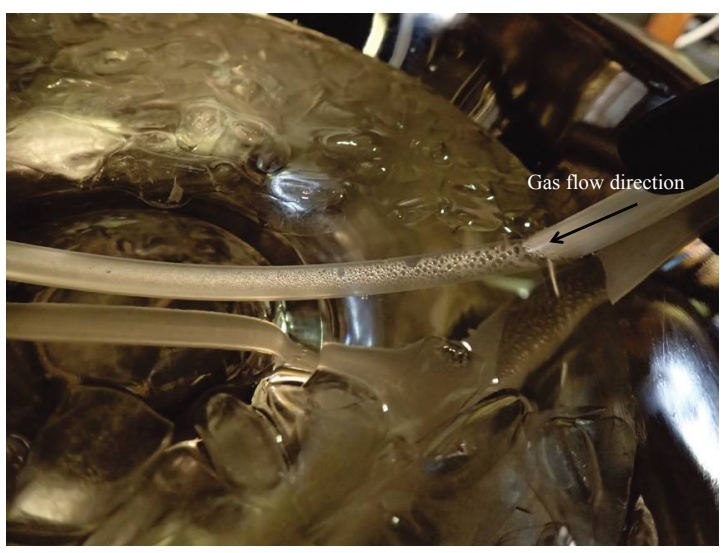

Figure 8. Initial condenser used for water capture tests showing significant condensation at entrance to ice bath compared to exit.

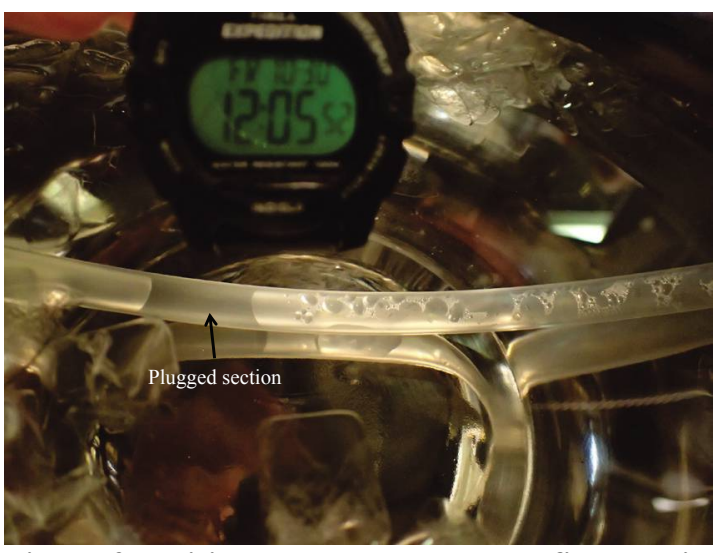

Figure 9. Initial condenser tube filled with liquid water in lowest portion.

\section{B. Soil Heating Results}

A second aspect of the overall concept is the ability to radiatively heat the wet soil as the rototiller brings fresh regolith to the surface. For these tests the bin was filled with $9 \mathrm{~cm}$ of hand-compacted GRC-3 simulant. ${ }^{7}$ The simulant was 'room-dry', which would be the lowest specific heat, approximately $0.8 \mathrm{~J} / \mathrm{gm}-\mathrm{K}$ based on values for basalt and quartz sand. Thermocouples were placed in the soil on the right side of the bin at the surface and at 1,3, and $4 \mathrm{~cm}$ below the simulant surface. A fifth thermocouple was placed on the left side of the bin at $1 \mathrm{~cm}$ below the 
simulant surface. While the heaters were rated at $500 \mathrm{~W}$, their operating temperature limit of $200{ }^{\circ} \mathrm{C}$ resulted in limiting the power to approximately $165 \mathrm{~W}$ of total power for both heater top plates. Figure 10 shows the temperature response of the heater plates and the soil. Power into the two heaters was increased in steps (at

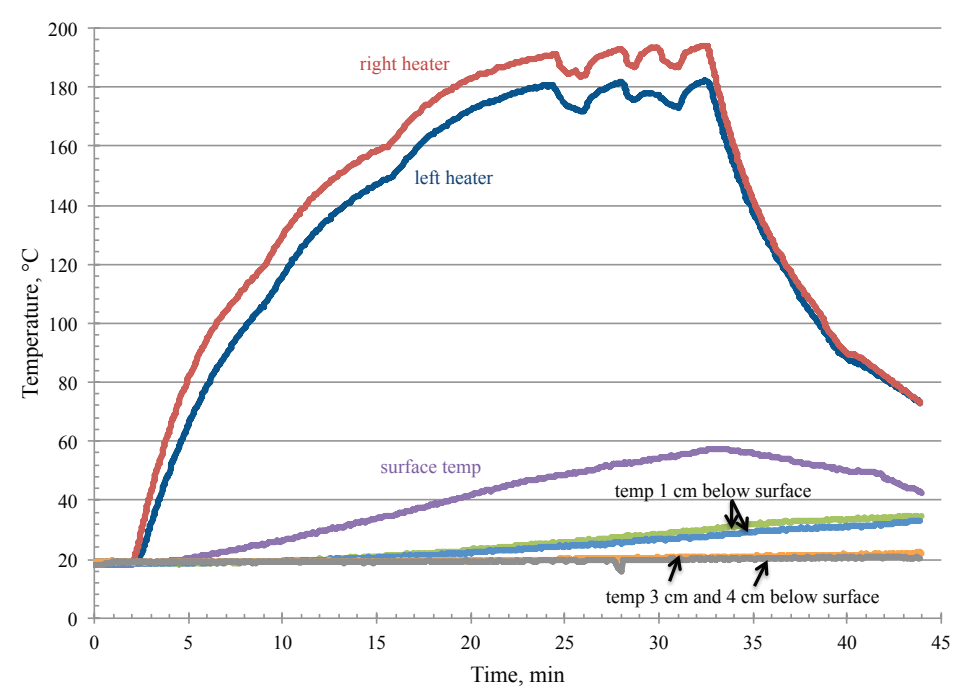

Figure 10. Heater and soil responses during soil heating test.

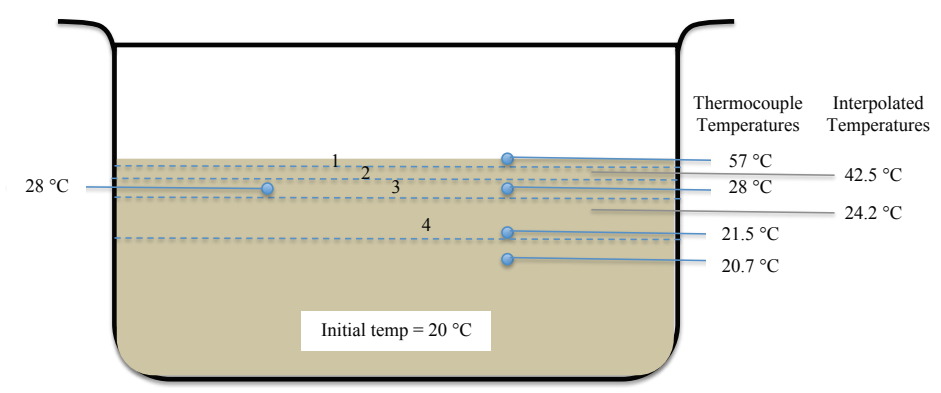

Figure 11. Location of thermocouples and division of temperature zones for energy calculations.

Table I. Calculation of total energy absorbed by soil.

$\begin{array}{lcllll}\text { Surface Area } & 1100 & \mathrm{~cm} 2 & \text { Density } & 1.5 & \mathrm{gm} / \mathrm{cm} 3 \\ \text { Specific Heat } & 0.8 & \mathrm{j} /(\mathrm{gm}-\mathrm{K}) & \text { Initial Temp } & 20 & { }^{\circ} \mathrm{C}\end{array}$

\begin{tabular}{|c|c|c|c|c|c|c|}
\hline Zone & $\begin{array}{c}\text { Thickness, } \\
\mathrm{cm}\end{array}$ & $\begin{array}{c}\text { Volume, } \\
\mathrm{cm} 3\end{array}$ & $\begin{array}{c}\text { Mass, } \\
\mathrm{gm}\end{array}$ & $\begin{array}{c}\text { Temp, } \\
{ }^{\circ} \mathrm{C}\end{array}$ & $\begin{array}{c}\text { Delta T, } \\
{ }^{\circ} \mathrm{C}\end{array}$ & $\begin{array}{c}\text { Absorbed } \\
\text { Energy, } \mathrm{j}\end{array}$ \\
\hline 1 & 0.25 & 275 & 412.5 & 57 & 37 & 12210 \\
2 & 0.5 & 550 & 825 & $42.5^{*}$ & 22.5 & 14850 \\
3 & 0.5 & 550 & 825 & 28 & 8 & 5280 \\
4 & 2 & 2200 & 3300 & $24.2 *$ & 4.2 & 11088 \\
\hline
\end{tabular}
approximately 9 minutes and 15 minutes) until the power level was found that would maintain the heater temperatures at no more than $200{ }^{\circ} \mathrm{C}$. The fans were cycled on and off several times to observe the effect on the heaters and soil. While there is no obvious response in the soil temperatures, the fluctuations in the heater plate temperatures (between 25 and 35 minutes) is a clear indication that the fans create sufficient flow to create some convective heat transfer.

After $30 \mathrm{~min}$ of heating the surface temperature reached $57{ }^{\circ} \mathrm{C}$. The poor conductivity of the simulant resulted in much lower temperatures below the surface. The total energy absorbed by the simulant was calculated by separating the heated portions into 4 zones, as shown in Fig. 11. Zones 1 and 3 used the actual thermocouple temperatures at the surface and $1 \mathrm{~cm}$ below the surface; zones 2 and 4 used interpolated temperature values based on the actual thermocouple data. Because the measured temperature at $1 \mathrm{~cm}$ below the surface was significantly lower than the measured surface temperature, the high temperature at the surface was assumed to cover only the first $0.25 \mathrm{~cm}$ of depth. Zones 2,3 , and 4 were then assumed to be 0.5 , 0.5 , and $2 \mathrm{~cm}$ thick, respectively. Table I lists the thickness and temperature used for each zone, and the resulting calculated energy absorbed to raise the temperature. Using this method of approximations, the total energy absorbed by the soil was just under 45,000 joules.

Using data from the power supplied to the heater as a function of time, the total energy supplied to the heaters during the test was approximately 260,000 joules. While the heaters, insulation, and geometry were very simplistic and non-optimized for this application, comparing these two energy calculations shows that approximately 17 percent of the energy supplied was absorbed by the simulant bed.

\section{Water Extraction Results}

The final aspect of the overall concept is the ability of a real-time digging implement to expose fresh regolith to the low pressure, heated environment such that water in the regolith evolves into the moving air stream. For these tests the bin was filled with $7 \mathrm{~cm}$ of hand-compacted GRC-3 simulant with 5 percent-by-weight water added, and then $2 \mathrm{~cm}$ of room-dry GRC-3. The rototiller tines were pre-buried in the simulant before the chamber was sealed. 
Once the chamber pressure reached the set pressure of 7 Torr, the make-up gases were turned off, and the fans were turned on. The back pressure valve was set to maintain chamber pressure at 7 Torr. Even without any heat added to the soil, condensation drops were immediately visible on the walls of the condenser tube where it entered the ice bath. This is an indication that the room-dry surface soil was being dried out by exposure to the low pressure and air current.

Figure 12 shows the temperature of the two heater plates, the chamber pressure, and the approximate accumulated water column height during this test. The rate of water evolution from the 'dry' surface soil appeared to be slowing down (around minute 16), then increased as the heaters reached their operating temperature. The rototiller was turned on for two passes through the soil bin at 32 minutes and 41 minutes into the test. There was a sharp increase in the rate of water collection with the rototiller activity. Indications of water evolution can also be seen in the chamber pressure and the heater plate temperatures reactions. Between 48 and 59 minutes the rototiller was run continuously through the soil with some additional reaction in chamber pressure and heater plate temperatures. Total water accumulated during this test was approximately 8 gms.

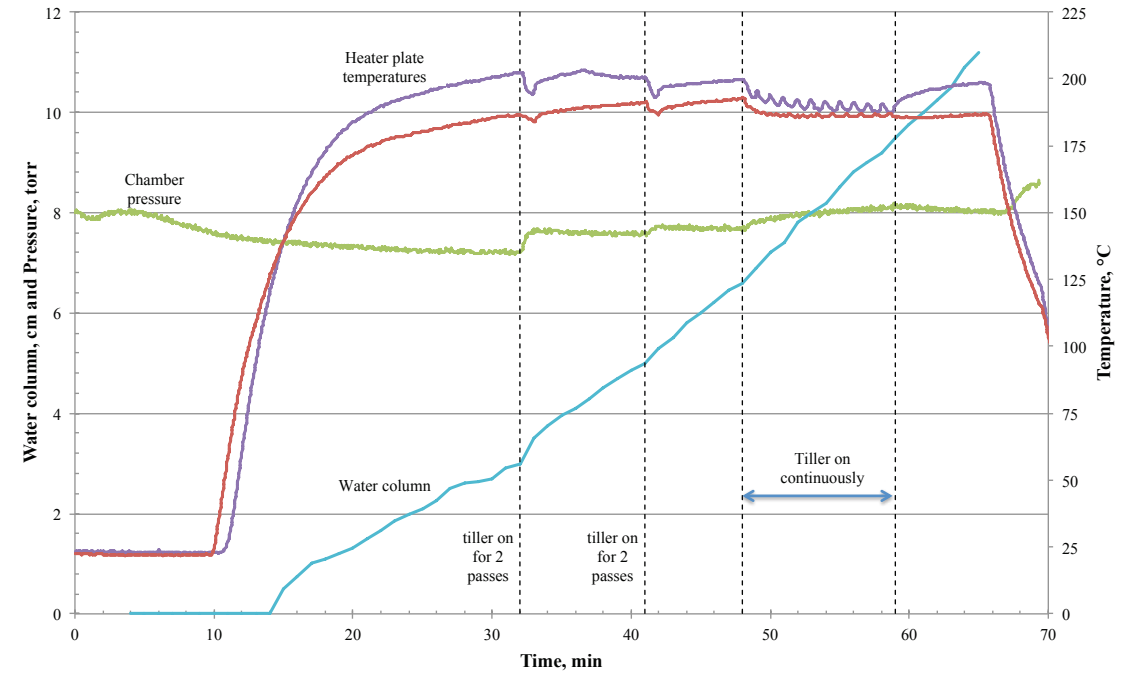

Figure 12. Heater temperatures and water accumulation for rototiller test in GRC-3 simulant with 5 weight-percent water.

\section{Conclusions}

A new concept for extraction of water from the Mars soil that utilizes the Mars atmosphere as a sweep gas in an 'open-air' system was tested for feasibility in a Mars environment chamber. An enclosure, intended to emulate the bottom of a rover, covered a soil bin to provide flow containment and a radiative heat source. The system successfully volatilized water from a doped soil bed and conveyed and captured that vapor into a condenser, thus demonstrating feasibility of the concept as a whole. Further refinement of the elements is needed to demonstrate applicability.

The radiant heat source used in this breadboard was able to modestly increase the temperature of the soil surface to encourage water release. In application, the preferred concept of operation would be to process the soil during roving. This would require a more efficient heating process to achieve high enough temperatures to target hydrated minerals in the surface soil. Likewise, a faster heating rate is needed to keep up with roving timelines. Possible options include a more efficient radiant source, moving the source closer to the surface, or possibly implementing an alternative approach such as a heated tiller.

Two simple off-the-shelf fans were able to create sufficient flow at 7 Torr to carry moist air through a $0.95 \mathrm{~cm}$ condenser line where the water was captured. Initial testing using a desiccant bed involving a more complex flow loop with smaller passages resulted in little water capture, indicating the importance of a well-designed water capture system to maintain gas flow at these low Mars pressures.

A rototiller was used to churn up the soil and expose fresh moist soil to the surface to increase the rate of water extraction. Including such devices under a rover, or even as part of its drive mechanism, can therefore help to expedite water extraction in a mobile harvester. The initial modest success of these three key aspects indicates a basic feasibility of this novel water acquisition concept. 


\section{Acknowledgments}

The authors gratefully acknowledge the support of this work by the Glenn Research Center Innovation Fund, which is funded by the NASA Space Technology Mission Directorate.

\section{References}

${ }^{1}$ Drake, B.G., "Human Exploration of Mars Design Reference Architecture 5.0, Executive Summary," February 2009 (available from http://ntrs.nasa.gov/archive/nasa/casi.ntrs.nasa.gov/20090012109.pdf)

${ }^{2}$ Drake, B.G. (editor), "Human Exploration of Mars Design Reference Architecture 5.0 Addendum," NASA-SP-2009-566ADD, July 2009.

${ }^{3}$ Hegde, U., Balasubramaniam, R., and Gokoglu, S., "Development and Validation of a Model for Hydrogen Reduction of JSC-1A,” AIAA-2009-1389, January 2009.

${ }^{4}$ Linne, D.L., "Employing ISRU Models to Improve Hardware Design,” AIAA 2010-800, January 2010.

${ }^{5}$ Thakur, T.C., Godwin, R.J., "The Present State of Force Prediction Models for Rotary Powered Tillage Tools," Journal of Terramechanics, Volume 26, Issue 2, 1989, Pages 121-138, ISSN 0022-4898.

${ }^{6}$ Linne, D.L., Gaier, J.R., Zoeckler, J.G., Kolacz, J.S., Wegeng, R.S., Rassat, S.D., and Clark, D.L., "Demonstration of Critical Systems for Propellant Production on Mars for Science and Exploration Missions," AIAA 2013-0587.

${ }^{7} \mathrm{He}, \mathrm{C}$., Zeng, X., and Wilkinson, A., “Geotechnical Properties of GRC-3 Lunar Simulant,” J. Aerosp. Eng., Vol 26, Issue 3, pg 528-534, July 2013, (doi: 10.1061/ (ASCE)AS.1943-5525.0000162). 